\title{
Risk Groups in a Multicenter Pilot Study for Treatment of Acute Lymphoblastic and Acute Undifferentiated Leukemia in Adults*
}

\author{
D. Hoelzer, E. Thiel, H. Löffler, H. Bodenstein, T. Büchner, R. Engelhardt, A. Ganser, \\ D. Messerer, H. Rühl, and T. Zwingers
}

\section{A. Introduction}

The German Multicenter Trial for Adult Acute Lymphoblastic (ALL) and Acute Undifferentiated (AUL) Leukemia was undertaken to improve remission duration by using a modified form of an intensified induction regimen successful in childhood ALL (Riehm et al. 1980). The results from the pilot study, with a total of 162 patients and a median observation time of $4 \frac{1}{2}$ years, now allow some conclusions regarding prognostic factors which influence the achievement of complete remission or the length of remission.

\section{B. Treatment}

The concept of this therapeutic trial was to eradicate as much as possible of the initial tumor cell load by an eight-drug induction therapy and a similarly intensive early consolidation therapy after 3 months, whereas the maintenance therapy is conventional with 6-mercaptopurine and methotrexate. The 8-week induction regimen consists of two phases: In the first 4 weeks prednisone $60 \mathrm{mg} / \mathrm{m}^{2}$ PO daily, vincristine $1.5 \mathrm{mg} / \mathrm{m}^{2}$ IV once weekly, daunorubicin $25 \mathrm{mg} / \mathrm{m}^{2}$ IV once weekly, and l-asparaginase 5000 units $/ \mathrm{m}^{2}$ IV on days $1-14$; and in the second 4 weeks cyclophosphamide $650 \mathrm{mg} / \mathrm{m}^{2}$

* German Multicenter Trial for Adult ALL/ AUL, FRG. Supported by the Bundesministerium für Forschung und Technologie, Contract No. 01 ZW 450
IV 3 doses at 2-week intervals, cytosine arabinoside $75 \mathrm{mg} / \mathrm{m}^{2}$ IV on 4 days per week for 4 weeks, and 6-mercaptopurine $60 \mathrm{mg} / \mathrm{m}^{2}$ PO daily for 4 weeks. CNS prophylaxis consists in methotrexate $10 \mathrm{mg} / \mathrm{m}^{2}$ intrathecally each week and CNS irradiation with 24 Gy. A 6-week reinduction course is given after 3 months and is similar to the induction regimen, adriamycin being substituted for daunorubicin, dexamethasone for prednisone, and thioguanine for 6-mercaptopurine; L-asparaginase is omitted. Maintenance therapy with 6 -mercaptopurine $60 \mathrm{mg} / \mathrm{m}^{2} \mathrm{PO}$ daily and methotrexate $20 \mathrm{mg} / \mathrm{m}^{2}$ PO or IV once weekly is continued for 2 years. Further details of the therapy and of the diagnostic procedure have been described previously (Hoelzer et al. 1984).

\section{Results}

From October 1978 to June 1981 a total of 162 adult patients from 25 hospitals entered the study, and $126(77.8 \%)$ achieved complete remission. At the evaluation date, 30 November 1983, the median survival time for all patients was 23.4 months and that for complete remitters was 34 months. Median remission duration was 20.5 months. The probability of being in complete remission at $4 \frac{1}{2}$ years is 0.397 . Cell marker analysis identified c-ALL in $56.4 \%$, null-AL (defined as being non-B-ALL, non-T-ALL, cALLA ${ }^{-}$) in $25.6 \%$, T-ALL in $15.4 \%, \mathrm{~B}-\mathrm{ALL}$ in $0 \%$, and mixed leukemia in $2.6 \%$. The best results were achieved in patients with T-ALL, for whom the prob- 
Table 1. Prognostic factors for remission duration: Pilot study

\begin{tabular}{llllll}
\hline Factor & & $\begin{array}{l}n \\
(126)\end{array}$ & $\begin{array}{l}\text { MRD } \\
\text { (months) }\end{array}$ & $\begin{array}{l}\text { In continu- } \\
\text { ous CR }\end{array}$ & P-value \\
\hline Age & $\leqq 35$ years & 98 & 24.9 & $42.9 \%$ & 0.0150 \\
& $>35$ years & 28 & 12.7 & $28.6 \%$ & \\
Leukocyte count & $\leqq 30000 / \mu 1$ & 85 & 28.0 & $44.7 \%$ & 0.0314 \\
& $>30000 / \mu \mathrm{l}$ & 41 & 14.8 & $29.3 \%$ & \\
Time to achieve CR & Within 4 weeks & 94 & 28.2 & $42.6 \%$ & 0.0285 \\
& After 4 weeks & 32 & 11.8 & $31.3 \%$ & \\
Immunological subtype & c-ALL & 32 & 23.4 & $48.8 \%$ & 0.0143 \\
& T-ALL & 11 & m.n.r. & $63.6 \%$ & \\
& null-AL & 16 & 12.7 & $12.5 \%$ & \\
\hline Low-risk group & & 19 & m.n.r. & $79.0 \%$ & 0.0000 \\
High-risk group & & 40 & 11.8 & $20.0 \%$ & \\
\hline
\end{tabular}

a Median not reached

ability of being in continuous complete remission at $4 \frac{1}{2}$ years is 0.636 .

\section{Prognostic Factors and Risk Groups}

Regarding the complete remission rate, none of the initial laboratory or clinical features, such as age, leukocyte count, hepatosplenomegaly, mediastinal tumor, CNS involvement, or other organ infiltration, had an unfavorable influence on the achievement of complete remission. The adverse effect of older age, high initial leukocyte count, and hepatosplenomegaly, which have been shown in other studies to have an unfavorable influence on the achievement of complete remission, could not be confirmed in the large number of patients in this study (Hoelzer et al. 1984).

\section{Prognostic Factors}

Prognostic factors for remission duration (Table 1) were time required to achieve remission, initial leukocyte count, immunological subtype, and age.

Age. The difference in remission duration for patients above and below 35 years of age was evident. In earlier studies (Hoelzer 1984) higher age was also found to exert an unfavorable influence on the survival time and remission duration. This multicenter ALL/AUL study has proved that results for older patients who did not require any essential omissions or reductions in the therapy program were similar to those for younger patients. The main problem is that for many of the older patients it is not possible to carry out the complete therapy schedule.

Leukocyte Count. In this therapy study, as in other ALL studies in adults (Schauer et al. 1983) or children, a high initial leukocyte count was found to be unfavorable for a long remission.

Immunological Subtype. The best prognosis in this study was for the subtype T-ALL, for which the median remission duration has not yet been reached. This finding is remarkable, since up to now patients with T-ALL, who frequently have a high initial leukocyte count, a mediastinal tumor, or CNS involvement, have had a poor prognosis. The worst prognosis, in keeping with findings from another study (Lister et al. 1979), was for patients with null-AL, who had a median remission duration of 13 months. Of the patients with c-ALL, 44\% were disease-free at the evaluation date.

Time Required to Achieve Complete Remission. The length of treatment required to achieve complete remission had the 
strongest influence on remission duration. Late response to therapy probably reflects a primarily more resistant population of leukemic cells. Other adult ALL therapy studies have also shown that of a total of $70 \%$ remission patients, only $50 \%$ achieved remission within 4 weeks (Hoelzer 1984). In childhood ALL the proportion of patients who reach complete remission after prolonged treatment is very low $(<5 \%)$. For them, it is also true that late response to therapy is correlated with a very poor prognosis (Frei and Sallan 1978).

\section{Definition of Risk Groups}

On the basis of these factors found to have prognostic significance for remission duration in the pilot study, it was possible to define groups of patients exposed to different degrees of risk. Those defined as low-risk patients are the ones who have none of the four risk factors, in comparison to high-risk patients who have one or more of the four risk factors. At the last evaluation date of 30 November 1983, 79\% of the low-risk patients were still in first remission, whereas only $20 \%$ of the high-risk patients were still free of disease.

\section{E. Risk-Adapted Therapy Protocol}

The study group has developed a new riskadapted therapy protocol based on the results of the pilot study, which was activated on 1 July 1983. According to this, in addition to the intensive induction therapy and consolidation therapy, high-risk patients will receive further cycles of consolidation therapy with VM-26 and cytosine arabinoside, to improve results in this group. In addition, the high-risk patients are to be considered for allogeneic bone marrow transplantation in first remission if a suitable donor is available. After establishment of the method, autologous bone marrow transplantation also appears to be useful for these patients. The low-risk patients will be treated according to the present protocol with no essential changes. It is to be expected that in this group, even with chemotherapy alone, more than 50\% will reach the 5-year limit without disease and might thereby be considered as cured.

\section{References}

Frei E, Sallan SE (1978) Acute lymphoblastic leukemia: treatment. Cancer 42:828-838

Hoelzer D (1984) Current status of ALL/AUL therapy in adults. In: Thiel E, Thierfelder S (eds) Leukemia. Springer, Berlin Heidelberg New York Tokyo, pp 182-203 (Recent results in cancer research, vol 93)

Hoelzer D, Thiel E, Löffler $H$, Bodenstein $H$, Plaumann L, Büchner T, Urbanitz D, Koch P, Heimpel H, Engelhardt R, Müller U, Wendt FC, Sodomann H, Rühl H, Herrmann F, Kaboth W, Dietzfelbinger H, Pralle H, Lunscken C, Hellriegel K-P, Spors S, Nowrousian RM, Fischer J, Fülle H, Mitrou PS, Pfreundschuh M, Görg C, Emmerich B, Queisser W, Meyer P, Labedzki L, Essers U, König H, Mainzer K, Herrmann R, Messerer $\mathrm{D}$, Zwingers $\mathrm{T}$ (1984) Intensified therapy in acute lymphoblastic and acute undifferentiated leukemia in adults. Blood 64:38-46

Lister TA, Roberts MM, Brearly RL, Woodruff RK, Greaves MF (1979) Prognostic significance of cell surface phenotype in adult acute lymphoblastic leukaemia. Cancer Immunol Immunother 6:227-230

Riehm H, Gadner H, Henze G, Langermann H-J, Odenwald E (1980) The Berlin childhood acute lymphoblastic leukemia therapy study, 1970-1976. Am J Pediatr Hematol Oncol 2:299-306

Schauer P, Arlin ZA, Mertelsmann R, Cirrincione C, Friedman A, Gee TS, Dowling M, Kempin S, Straus DJ, Koziner B, McKenzie S, Thaler HT, Dufour P, Little C, Dellaquila C, Ellis S, Clarkson B (1983) Treatment of acute lymphoblastic leukemia in adults: Results of the L-10 and L-10M protocols. J Clin Oncol 1:462-470 